\title{
A SINCRONIZAÇÃO DA TOMADA DE DECISÃO ESTRATÉGICA COM O PLANEJAMENTO EST'RATÉGICO FORMAL
}

\section{THE SINCHRONIZATION OF THE STRATEGIC DECISION-MAKING WITH THE FORMAL STRATEGIC PLANNING}

\section{WALTER BATAGLIA}

Doutor em Administração pela Faculdade de Economia, Administração e Contabilidade da Universidade de São Paulo (USP). Professor Assistente pelo Centro de Ciências Sociais e Aplicadas da Universidade Presbiteriana Mackenzie (UPM). Rua Consolação, 896, prédio T, Consolação - São Paulo - SP - CEP 01302-907 E-mail: batagliaw@terra.com.br

\section{ABRAMAM SIN OIH YU}

Livre-docente pela Faculdade de Economia, Administração e Contabilidade da Universidade de São Paulo (USP). Professor Associado da Faculdade de Economia, Administração e Contabilidade da Universidade de São Paulo (USP). Avenida Prof. Luciano Gualberto, 908, Cidade Universitária - São Paulo - SP - CEP 05508-010 E-mail: abraoyu@ipt.br 


\section{RESUMO}

A dinamicidade do ambiente competitivo pode tornar uma decisão programada no plano orçamentário inviável no período entre a aprovação no planejamento estratégico e o início da implementação. Por outro lado, o aproveitamento de oportunidades pode gerar a necessidade da tomada de uma decisão potencialmente vantajosa não contemplada no plano operacional. O objetivo deste estudo é analisar como as empresas sincronizam a tomada de decisão estratégica com o planejamento estratégico formal. A metodologia utilizada foi o estudo de casos múltiplos. Os casos foram colhidos de quatro agroindústrias do Estado de São Paulo. A análise revelou que as decisões programadas no plano orçamentário são reavaliadas e autorizadas pela alta administração imediatamente antes da primeira alocação de capital. Novas decisões não previstas no plano orçamentário são autorizadas via realocação ou suplementação de verbas. Em ambos os casos, o processo de autorização é centralizado e formal.

\section{PALAVRAS-CHAVE}

Tomada de decisão estratégica; Processo decisório estratégico; Planejamento estratégico; Estratégia organizacional; Administração estratégica.

\section{ABSTRACT}

The dynamicity of the competitive environment can become a decision included in the operational plan unfeasible in the period between its approval in the strategic planning and the beginning of its implementation. By the other side, in order to profit by opportunities it may be need making a potentially worthwhile decision not contemplated in the operational plan. The aim of this study is to analyze how companies synchronize the strategic decision-making with the formal strategic planning. The methodology used was the multiple case study. Cases were caught from four agribusiness companies of the State of São Paulo. The analysis revealed 
that decisions programmed in the budgetary plan are revaluated and authorized by top management immediately before the first capital allocation. New decisions not included in the budgetary plan are authorized by reallocation or supplementation of budgets. In both cases, the authorization process is centralized and formal.

\section{KEYWORDS}

Strategic decision-making; Strategic decision-making process; Strategic planning; Organizational strategy; Strategic management.

\section{INTRODUÇÃO}

O planejamento estratégico formal tem a função de aprovar e programar a implementação das decisões estratégicas, gerando um plano operacional e orçamentário (MINTZBERG, I994). Usualmente, o plano orçamentário é utilizado para controle. E o plano operacional é revisado anualmente, embora esse período possa variar de setor para setor.

No entanto, quando as decisões estratégicas envolvem variáveis do ambiente competitivo, caracterizadas pela instabilidade, surgem dois problemas. Por um lado, o dinamismo das variáveis gera incerteza no processo decisório estratégico, impossibilitando o estabelecimento de relação clara entre as alternativas de ação e suas conseqüências futuras (TUNG, I979; RANDOLPH; DESS, I984; BAUM; WALLY, 2003). Nesse sentido, variáveis ambientais podem sofrer alterações entre a aprovação do plano operacional e o início da implementação das decisões. Contudo, a duração do processo decisório estratégico é pressionada pela necessidade de aproveitamento de oportunidades, exigindo das firmas decisões rápidas (EISENHARDT, I989a; JUDGE; MILLER, I99I; BAUM; WALLY, 2003). Novas decisões potencialmente vantajosas podem surgir e não haver tempo suficiente para aguardarem o período seguinte de planejamento para sua aprovação. Coloca-se, então, a questão diretriz deste estudo: Como as empresas sincronizam o planejamento estratégico formal com o processo decisório estratégico?

Para responder a essa questão, o presente trabalho utiliza no plano conceitual um corte epistemológico que foca uma visão transversal sobre a tomada de decisão estratégica e o planejamento estratégico. No plano empírico, explora o ambiente complexo e de rápida mudança da tecnologia de informação, o qual além de gerar janelas de oportunidade também é fonte de incerteza para o processo decisório (EISENHARDT, I989a; ALPAR; KIM, I990; ENGEMANN; MILLER, I999; SEDDON; GRAESER; WILLCOCKS, 2002; EDQUIST, 2002; 
STEINMUELLER, 2002). A pesquisa utilizou o método de estudo de casos múltiplos. Estudaram-se decisões estratégicas e suas relações com o planejamento estratégico em quatro organizações do setor de processamento de alimentos da economia brasileira.

Observou-se que a aprovação de decisões não ocorre no planejamento estratégico, conforme proposto por Mintzberg (I994), mas somente sua programação, a qual é suscetível de revisão pelas organizações. Os resultados obtidos induziram rudimentos de um modelo que relaciona a implementação das decisões estratégicas com o planejamento estratégico formal, a estratégia organizacional, o processo decisório estratégico e a alta administração.

Estruturou-se o artigo em cinco seções além desta introdução. Na primeira e segunda seção sumarizam-se, respectivamente, as abordagens teóricas sobre tomada de decisão estratégica e planejamento estratégico. Na terceira seção, se apresenta a metodologia utilizada na pesquisa. Na quarta seção, se desenvolve uma síntese do perfil das empresas e dos processos decisórios estudados. Na quinta seção se apresentam as proposições derivadas da pesquisa. Por fim, na conclusão se resgatam as principais contribuições do estudo e algumas questões pertinentes que podem ser objeto de estudos futuros na área de administração estratégica.

\section{TOMADA DE DECISÃO ESTRATÉGICA}

Este trabalho se concentra na teoria administrativa sobre a tomada de decisão estratégica. Admite-se que decisão organizacional é um comprometimento específico para a ação (usualmente de recursos), e que o processo decisório é o conjunto de ações e fatores dinâmicos que começam com a identificação de um estímulo inicial para a ação e terminam com o comprometimento para ela (MINTZBERG; RAISINGHANI; THÉORÊT, I976; EISENHARDT; ZBARACKI, I992). A decisão é estratégica quando considerada importante pelos gestores da alta administração em termos das ações tomadas, dos recursos comprometidos ou dos precedentes estabelecidos. Além disso, seu processo decisório é não-estruturado, ou seja, é novo, incerto, não ocorreu anteriormente; para ele não existe um conjunto explícito e predeterminado de respostas ordenadas na organização. Operacionalmente, a decisão é estratégica quando: envolve posicionamento estratégico, apresenta altos riscos, envolve diversas funções organizacionais, e é considerada representativa das decisões da organização (EISENHARDT, I989a). A decisão estratégica possui duas dimensões centrais independentes: a racionalidade limitada e a política organizacional (DEAN; SHARFMAN, I993; EISENHARDT; ZBARACKI, I992). A seguir se apresenta uma síntese da literatura sobre essas dimensões. 


\subsection{A RACIONALIDADE LIMITADA NO PROCESSO DECISÓRIO}

Para Eisenhardt e Zbaracki (I992), o modelo da ação racional tem como pressuposto o fato de que o comportamento humano é calculado e instrumental. Os atores em uma situação de escolha possuem objetivos predeterminados e buscam informações apropriadas para estabelecer alternativas de ação. O valor das conseqüências dessas alternativas é determinado pelos objetivos. Diversos trabalhos mostraram limitações desse modelo. March e Simon (I993) e Cyert e March (I992) desenvolveram uma crítica geral, concluindo que o ser humano busca satisfazer e não maximizar, e que existem limites cognitivos no comportamento humano. Esses autores destacam o fato de que informações não estão disponíveis, precisam ser buscadas. E, freqüentemente, esse processo interfere na escolha; por exemplo, pela priorização das preferências individuais. Também identificam, de forma similar a Anderson (I983) e Pinfield (I986), que os objetivos, em geral, não são claros e mudam com o tempo, podendo ser redefinidos ao longo da busca por informações. Carter (I97I) aponta que a busca por informações é, usualmente, casual e oportunista. Langley (I989) mostra que a análise pode ser limitada. E Allison (I97I) afirma que as decisões podem refletir o uso de procedimentos padrão, e não a análise sistemática.

Mintzberg, Raisinghani e Théorêt (I976), influenciados pelos estudos de Simon (I960) e Witte (I972), propõem o Modelo Geral do Processo Decisório Estratégico, apresentado na Figura I. O modelo é composto de três fases: identificação, desenvolvimento e seleção. Destaca-se no modelo a idéia de que não existe uma relação seqüencial e simples entre as fases.

\section{FIGURA I}

\section{MODELO GERAL DO PROCESSO DECISÓRIO ESTRATÉGICO}

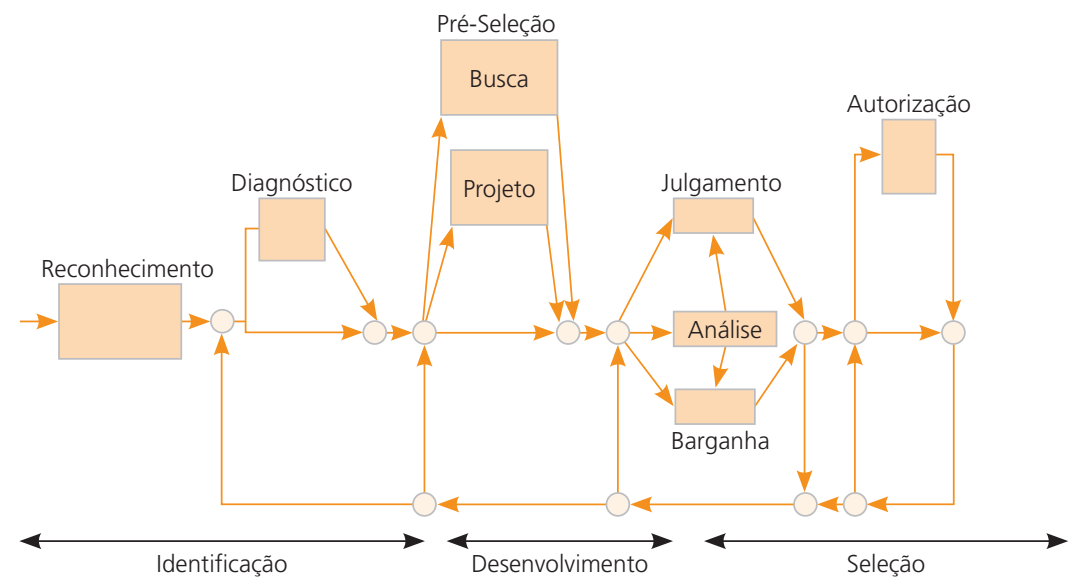

Fonte: Mintzberg, Raisinghani e Théorêt (I976, p. 266). 
Para os autores, cada fase é constituída por rotinas. Na fase de identificação ocorrem as rotinas de reconhecimento e diagnóstico. Na rotina de reconhecimento, oportunidades, problemas e crises são reconhecidos. Na rotina de diagnóstico se organiza a informação disponível e se levantam eventuais novas informações para formulação do problema. Na fase de desenvolvimento, ocorrem as rotinas de busca e projeto. A rotina de busca é utilizada para se procurarem soluções prontas ou semiprontas no ambiente externo à organização. A rotina de projeto é utilizada para desenvolver soluções customizadas, ou seja, concebidas especialmente para a decisão. Essa rotina é também utilizada para modificar soluções existentes fora da organização, adaptando-as a situações particulares. Na fase de seleção, ocorrem as rotinas de pré-seleção, avaliação-escolha e autorização. A rotina de pré-seleção é utilizada para eliminar o que é inviável quando o processo de busca gera mais soluções externas do que seria possível se avaliar. A rotina de avaliação aparece em três modos: julgamento de valor, quando um indivíduo utiliza sua intuição para escolher sem justificar suas razões; barganha, quando as partes envolvidas na decisão chegam a um consenso; e análise, quando ocorre avaliação factual. A rotina de autorização acontece quando os atores envolvidos no processo de avaliação não possuem a autoridade necessária para comprometer a organização em determinado curso de ação. A autorização pode ocorrer em níveis hierárquicos superiores, ou mesmo fora da organização, por atores do ambiente que detêm $o$ poder de bloquear a decisão.

Além das rotinas principais descritas, existem rotinas de suporte que podem ser iniciadas a partir de qualquer uma das fases do processo decisório. São elas as rotinas de controle, de comunicação e políticas.

As rotinas podem aparecer em qualquer ordem. Dessa forma, o processo decisório pode se repetir, alternar, ramificar, gerar ciclos e reciclar. Os fatores que auxiliam a explicar as mudanças de uma rotina para outra são designados fatores dinâmicos. São eles: interrupções, atrasos de cronograma, atrasos de realimentação, sincronizações, ciclos de compreensão e reciclagem por falhas. Interrupções são restrições inesperadas que causam a parada do processo decisório. Atrasos de cronograma podem ser utilizados para se aguardarem resultados de ações anteriores ou para dividir decisões complexas em passos administráveis. Sincronizações se referem a adiantamento ou atraso para se obterem vantagens de situações especiais. As reciclagens e ciclos de compreensão podem ser utilizados para se obter maior compreensão sobre uma situação. A linha principal através do centro do modelo mostra as duas rotinas mínimas de um processo decisório: reconhecimento da situação e avaliação-escolha. A linearidade do processo decisório é variável, dependendo do grau de reciclagem, da complexidade e do grau de política da decisão (HICKSON et al., I986).

A formulação inicial do processo decisório se baseia em quatro táticas (NUTT, I992). A primeira é da idéia, na qual os atores utilizam idéias existentes e buscam 
situações nas quais estas possam ser aplicadas. A segunda é a do problema, na qual os atores identificam algum tipo de problema e passam a buscar sua extinção. A terceira é a da meta, na qual um objetivo é assumido pelos atores. E a quarta é a tática de reenquadramento, na qual se busca melhorar a organização.

A fase de desenvolvimento se baseia em seis táticas (NUTT, I993). A primeira é a idéia, na qual o desenvolvimento de alternativas se baseia em uma idéia já existente anteriormente na organização. A segunda é o modelo simples, quando se adapta uma prática existente em outra organização, via visita ou coleta de dados. A terceira é o modelo composto, quando práticas de diversas organizações são adaptadas e compostas em um novo modelo para aplicação na organização. A quarta é a busca simples, em que as necessidades percebidas são utilizadas para se buscarem soluções externas que são avaliadas, escolhendo-se a melhor. A quinta é a busca composta, quando são utilizados ciclos de busca com o objetivo de aprimorar o entendimento da questão, utilizando-se, a cada novo ciclo, o conhecimento adquirido para especializar a especificação do problema e desenvolver novas buscas. E a sexta é o projeto, na qual se desenvolvem soluções customizadas ou modificadas.

Na rotina de avaliação se utilizam táticas analíticas, baseadas na barganha, subjetivas e de julgamento (NUTT, I998). As táticas analíticas correspondem à utilização de dados secundários, testes pilotos ou simulações. A barganha envolve o estabelecimento de consenso em grupo. Em seu estudo, Nutt (i998) diferenciou as escolhas baseadas em julgamento de valor pela apresentação ou não de justificativa. As escolhas que apresentam justificativas são classificadas como subjetivas, e as sem justificativas como julgamento.

\subsection{A PERSPECTIVA POLÍTICA NO PROCESSO DECISÓRIO ESTRATÉGICO}

A perspectiva política admite que as organizações são coalizões de pessoas com interesses distintos. Enquanto alguns objetivos podem ser compartilhados, outros estabelecem conflitos. As preferências conflitantes derivam de visões diversas sobre o futuro, vieses estabelecidos pelas posições distintas nas organizações e confronto de ambições e interesses (DEAN; SHARFMAN, I992). Os conflitos vividos nas organizações são definidos como processos percebidos por ambas as partes envolvidas em que haja incompatibilidades de interesses (PRUITT; CARNEVALE, I993; RUBIN; PRUITT; KIM, I994). A abordagem competitiva leva à utilização de táticas de influência. Nesse contexto, o poder é habilidade para fazer com que os outros se comportem de acordo com as preferências de outrem e de impor sanções caso contrário (ARENDT, I970). O comportamento político possui diversas dimensões: atividades que levam à aquisição e uso do poder visando 
objetivos próprios (PFEFFER, I992; EISENHARDT; BOURGEOIS, I989); táticas de informação (DEAN; SHARFMAN, I993; PETTIGREW, I973), isto é, manipulação e controle de canais importantes de informação; e táticas de uso do tempo e oportunismo para construir uma base de poder para as idéias (QUINN, I980).

Há alguns fatores individuais e organizacionais que influenciam no comportamento político (BIBERMAN, I985). Dentre os pessoais, destacam-se traços de personalidade, como autocontrole e necessidade de poder. Dentre os organizacionais, destacam-se a distribuição de recursos escassos, ambigüidade, tomada de decisão democrática e pressão para alto desempenho.

O centro da perspectiva política é o processo de solução de conflitos. Eisenhardt e Bourgeois (I988) analisaram o conflito entre executivos e observaram que a utilização de árbitros e mediadores para solução de conflitos está associada ao melhor desempenho em ambientes dinâmicos.

\subsection{ESTRATÉGIA E PLANEJAMENTO ESTRATÉGICO ORGANIZACIONAL}

Embora o tema estratégia tenha sido amplamente tratado na literatura, não há uma definição que seja universalmente aceita. Mintzberg (I987) ressalta as diversas e complementares dimensões da estratégia, defendendo que ela requer uma série de definições, em especial as cinco descritas no Quadro I.

\section{QUADRO I}

\section{DEFINIÇÕES DE ESTRATÉGIA}

A estratégia é um plano - algum tipo de curso de ação conscientemente engendrado, uma diretriz (ou um conjunto de diretrizes) para lidar com determinada situação.

A estratégia é um padrão - especificamente um padrão em um fluxo de ações. Em outras palavras, a estratégia é consistência no comportamento, quer seja pretendida ou não.

A estratégia é uma posição - especificamente, uma maneira de colocar a organização no ambiente competitivo. A estratégia é a força de mediação - ou harmonização - entre a organização e o ambiente, isto é, entre os contextos interno e externo.

A estratégia é uma perspectiva - seu conteúdo consistindo não apenas em uma posição escolhida, mas em uma maneira enraizada de ver o mundo. Isto é, a maneira fundamental de uma organização fazer as coisas.

A estratégia é um pretexto - apenas um truque, uma manobra específica para enganar um oponente ou concorrente. 
Este trabalho aceita que a estratégia é uma posição, ou seja, uma proposição genérica de posicionamento da organização no meio ambiente competitivo. A natureza ou objeto do posicionamento refere-se a algo importante, assim definido pelos gestores da organização (RUMELT, I979). Revisando a literatura sobre estratégia organizacional, Mintzberg, Ahlstrand e Lampel (2000) identificaram dez pontos de vista distintos sobre modelos operacionais de formulação da estratégia, ou seja, planejamento estratégico. Designaram esses modelos de escolas de pensamento. Elas são apresentadas no Quadro 2.

\section{QUADRO 2}

\section{AS ESCOLAS DE PENSAMENTO SOBRE}

\section{A FORMULAÇÃO DA ESTRATÉGIA}

\begin{tabular}{|c|c|c|}
\hline ABORDAGEM & ESCOLA & DESCRIÇÃO \\
\hline \multirow[t]{3}{*}{ Prescritiva } & Design & $\begin{array}{l}\text { Foca a formulação da estratégia como um processo de } \\
\text { desenho informal, essencialmente de concepção (CHANDLER, } \\
\text { 1962). }\end{array}$ \\
\hline & Planejamento & $\begin{array}{l}\text { Desenvolveu-se paralelamente à escola do design. Teve sua } \\
\text { origem com Ansoff (1965). O processo de formulação não é só } \\
\text { cerebral, mas também formal, passível de decomposição em } \\
\text { passos distintos (principalmente com relação a objetivos, metas, } \\
\text { programas e planos operacionais). A estratégia é vista como o } \\
\text { meio de definir as tarefas gerenciais (HAX; MAJLUF, 1996). }\end{array}$ \\
\hline & Posicionamento & $\begin{array}{l}\text { Teve sua origem na escola do design. O processo de } \\
\text { formulação se reduz à definição de posições genéricas } \\
\text { selecionadas por análise formal da situação do setor (PORTER, } \\
\text { 1990). }\end{array}$ \\
\hline \multirow[t]{3}{*}{ Descritiva } & Empreendedora & $\begin{array}{l}\text { Centra o processo de formulação no executivo principal; } \\
\text { porém, diferentemente da escola do design e de forma oposta } \\
\text { à escola do planejamento, baseia o processo na intuição } \\
\text { (BUSENITZ; BARNEY, 1997). }\end{array}$ \\
\hline & Cognitiva & $\begin{array}{l}\text { A cognição é utilizada para construir estratégias como } \\
\text { interpretações criativas (REGER et al., 1994). }\end{array}$ \\
\hline & Aprendizado & $\begin{array}{l}\text { O processo é concebido como o padrão que dá unicidade, } \\
\text { coerência e integração às decisões. Ou seja, a estratégia } \\
\text { emana do que a organização faz. Cabe à administração } \\
\text { direcionar no sentido da visão definida (BURGELMAN, 1996). }\end{array}$ \\
\hline
\end{tabular}




\section{QUADRO 2 (CONTINUAÇÃO)}

\section{AS ESCOLAS DE PENSAMENTO SOBRE}

A FORMULAÇÃO DA ESTRATÉGIA

\begin{tabular}{cll}
\hline ABORDAGEM & ESCOLA & DESCRIÇÃO \\
\hline Poder & $\begin{array}{l}\text { O processo de formulação da estratégia é caracterizado } \\
\text { como um conjunto de ações de influência, enfatizando o } \\
\text { uso do poder e política para negociar estratégias favoráveis a } \\
\text { determinados interesses (MACMILLAN, 1978). }\end{array}$ \\
\hline Cultural & $\begin{array}{l}\text { O processo de formulação é visto como um conjunto de } \\
\text { interações sociais enraizado na cultura organizacional } \\
\text { (PRAHALAD; BETTIS, 1986). }\end{array}$ \\
\hline Configuraçãontal & $\begin{array}{l}\text { O processo é percebido como passivo e reage somente em } \\
\text { resposta ao ambiente (HANNAN; FREEMAN, 1977). }\end{array}$ \\
\hline buscando uma visão integrativa para o processo de \\
formulação (MILLE, 1996).
\end{tabular}

Fonte: Adaptado de Mintzberg, Ahlstrand e Lampel (2000).

A existência de abordagens alternativas à abordagem formal do planejamento estratégico leva a uma série de questões. Especialmente, sobre a necessidade ou mesmo a adequação da utilização do planejamento nas organizações. Isso gerou uma série de pesquisas sobre o tema. Fredrickson (1984) e Fredrickson e Iaquinto (I989) estudaram a relação entre a abrangência dos processos decisórios, conseguida por sua integração e formalização no planejamento, e o desempenho das organizações. Entendiam que a abrangência está correlacionada positivamente com o desempenho em ambientes estáveis, e negativamente em ambientes dinâmicos. Khandwalla (I970) encontrou correlação negativa entre o crescimento setorial e o planejamento estratégico. Outras pesquisas destacaram correlação positiva entre o tamanho da organização e o planejamento (SAPP, I980; AL-BAZZAZ; GINYER, I983).

Mintzberg (I994) defendeu a tese de que a gênese das estratégias não está no processo de formulação da estratégia, formulando uma das principais críticas ao planejamento estratégico. O argumento do autor é que a racionalidade formal está enraizada na análise, e não na síntese. Assim, o planejamento não poderia ser responsável pela formulação da estratégia que depende dos modelos intuitivos dos gestores. O planejamento estratégico teria a função de aprovar e programar a realização das estratégias já existentes na organização. Mintzberg 
(I994) levanta a hipótese de que as variáveis estabilidade ambiental, estrutura organizacional elaborada, inter-relações estratégicas operacionais e simplicidade das atividades são condições necessárias ao planejamento estratégico. E que as variáveis grau de intensidade de capital, tamanho, maturidade setorial e controle externo são condições facilitadoras do planejamento.

Para efeito desta pesquisa, considera-se que o planejamento estratégico é um procedimento formal que articula as decisões organizacionais em um sistema único de decisões integradas (MINTZBERG, I994). Essa definição reflete a essência do processo de formulação da estratégia uma vez que lida com as inter-relações entre as decisões organizacionais (importantes). Um dos seus pontos-chave é a ênfase na formalização. Simplesmente um conjunto de conceitos, procedimentos e testes (BRYSON, I988). A formalização implica decomposição, articulação e, especialmente, racionalização dos processos pelos quais as decisões são tomadas e integradas na organização. O planejamento é caracterizado pela decomposição natural da análise, possuindo uma natureza reducionista. Os planos devem ser práticos, factuais, lógicos e realistas no estabelecimento de objetivos, divisando meios para alcançá-los (STEINER, I969). O processo contrasta o sistemático com o casual (DENNING, I973). A pressuposição-chave é que a síntese seja possível pela articulação (ZAN, I987; STEINER, I969). Uma das implicações dessa definição é que as decisões são reunidas, periodicamente, em um processo único e integrado de forma que possam ser tomadas em um único ponto no tempo. Isso permite a operacionalização do construto planejamento, identificando-o com dois fenômenos observáveis nas organizações - o uso do procedimento formal e a existência de um resultado articulado, especificamente envolvendo um sistema de decisões integradas. O planejamento estratégico gera um plano operacional cujo período contemplado, ou horizonte de planejamento, varia de organização para organização, dependendo da natureza de seus negócios. O plano é revisado periodicamente, em geral, a cada ano, gerando um plano anual detalhado para o ano seguinte, tipicamente mais preciso (GUP, I980).

Vale ressaltar que este trabalho busca identificar a relação entre o processo decisório estratégico e o processo de planejamento.

\section{A METODOLOGIA DA PESQUISA}

Esta pesquisa escolheu o método de estudo de caso múltiplo (YIN, I994; BONOMA, I985) em função da ausência de controle sobre os eventos que se desejam estudar e a impossibilidade da separação do objeto de estudo do contexto (situações-problema reais de decisão estratégica, vividas em organizações). Utilizaram-se as técnicas de entrevista sistemática e, sempre que possível, de 
levantamento documental. Quanto à natureza das evidências, usaram-se evidências qualitativas (YIN, I994; EISENHARDT, I989b), as quais foram importantes na descrição dos processos decisórios estratégicos e de planejamento. Buscou-se reduzir a ocorrência de distorções e falhas provenientes da memória dos informantes de duas formas. A primeira foi a utilização de fontes múltiplas de dados, realizando-se entrevistas com os principais gestores que participaram do processo decisório. A segunda foi a elaboração de um sumário descritivo de cada processo decisório pesquisado e de sua relação com o planejamento estratégico. Quando observadas diferenças entre as descrições feitas pelos vários informantes, entrevistas adicionais eram realizadas para se reconciliarem os passos descritos em uma única lista de atividades (HUBER; POWER, I985). Imprecisões foram corrigidas pelos informantes até que os sumários se tornassem aceitáveis, ou seja, houvesse detalhes suficientes para se entender o que foi feito e acordo entre os informantes sobre a seqüência dos eventos (NUTT, I992, I993 е г998).

\subsection{ESCOLHA DAS EMPRESAS E COLETA DE DADOS}

O conjunto de empresas de interesse para a pesquisa foi definido como o formado pelas maiores empresas do setor de alimentos processados, segundo as vendas em US\$ milhões (EXAME, 2006). No nível ambiental, optou-se pela escolha de um único setor com o objetivo de controlar as diferenças operacionais e financeiras e seus efeitos sobre o objeto de estudo da pesquisa (EISENHARDT, I989b). A escolha do setor considerou sua capacidade de investimento e importância. Com relação às firmas, optou-se pela escolha das maiores empresas. Os objetivos foram: atender às condições favoráveis à existência do planejamento estratégico (estrutura organizacional elaborada, inter-relações estratégicas operacionais, simplicidade das atividades e tamanho) (MINTZBERG, I994); e reduzir variações devidas às diferenças nos tamanhos das empresas.

A definição das empresas foi realizada utilizando-se amostragem teórica (GLASER; STRAUSS, I967). Ou seja, os casos foram escolhidos por razões teóricas e não estatísticas, visando ampliar a teoria emergente e facilitar a replicação da pesquisa. A amostragem baseou-se na análise de fontes secundárias e em reuniões com estudiosos de associações setoriais. Conversou-se com especialistas do Programa de Estudos dos Negócios do Sistema Agroindustrial (Pensa), da Faculdade de Economia e Administração (FEA), da Universidade de São Paulo, e da Associação Brasileira das Indústrias da Alimentação (Abia). A seleção das organizações foi baseada na escolha de casos extremos e polares, buscandose ampliar as diferenças e similaridades do objeto de pesquisa (PETTIGREW, I988). As organizações foram selecionadas com base nos seguintes critérios: 
investimentos expressivos em tecnologia de informação; opção por investir ou não investir em determinadas tecnologias contrariamente aos concorrentes; e mudanças bruscas na postura com relação ao investimento em dada tecnologia ou no procedimento de análise de investimentos.

A caracterização do processo decisório estratégico foi realizada por meio do estudo aprofundado dos processos decisórios selecionados. A validade dessa abordagem deriva de pesquisas anteriores que mostram que as organizações tomam decisões estratégicas seguindo um padrão consistente (MINTZBERG; RAISINGHANI; THÉORÊT, I976; MILES; SNOW, I978; HICKSON et al., I986; FREDRICKSON; IAQUINTO, I989; EISENHARDT, I989a), mesmo quando ocorre rotatividade nas posições individuais da alta administração (WEICK, I979). O estudo dos processos decisórios selecionados foi realizado pela condução de entrevistas em profundidade, pessoais e individuais, com os gerentes envolvidos na decisão. As decisões a serem estudadas foram estabelecidas pelo gerente responsável pelas atividades de coordenação da TI, seguindo-se os seguintes critérios adaptados de Eisenhardt (i989a): envolver posicionamento estratégico; ser não estruturada, gerando incerteza; envolver o maior número possível de funções organizacionais; e ser considerada representativa do processo pelo qual as decisões estratégicas são tomadas na organização. Utilizaram-se múltiplos níveis de análise de dados (YIN, I994), conforme apresentado no Quadro 3.

QUADRO 3

NÍVEIS DE ANÁLISE DE DADOS

\begin{tabular}{|c|c|c|}
\hline NIVEIS DE ANÁLISE & TIPOS DE DADOS & TÉCNICAS DE COLETA \\
\hline $\begin{array}{l}\text { Processo decisório estratégico } \\
\text { de investimento em } \mathrm{TI}\end{array}$ & Perfil do processo decisório & $\begin{array}{l}\text { Entrevista em profundidade; } \\
\text { questionário; fontes } \\
\text { secundárias }\end{array}$ \\
\hline Planejamento estratégico & $\begin{array}{l}\text { Relação entre o processo } \\
\text { decisório e o planejamento } \\
\text { estratégico }\end{array}$ & $\begin{array}{l}\text { Entrevista em profundidade; } \\
\text { questionário; fontes } \\
\text { secundárias }\end{array}$ \\
\hline Grupo decisor & Nível gerencial & Fontes secundárias \\
\hline
\end{tabular}

Fonte: Elaborado pelos autores.

O processo decisório foi operacionalizado com base no modelo proposto por Mintzberg, Raisinghani e Théorêt (I976) e aprofundado por Nutt (I992, I993, I998). Considerou-se que o início do processo foi a primeira reunião na organi- 
zação na qual se discutiu a decisão. E que seu fim ocorreu na primeira alocação de recursos (capital) para implementação da decisão. Solicitou-se que os informantes descrevessem a seqüência de passos realizada para se tomar a decisão. Os informantes foram dirigidos por perguntas do tipo "O que aconteceu primeiro?" e "O que ocorreu a seguir?" feitas pelo pesquisador para permitir a reconstrução dos passos do processo decisório (NUTT, I984).

O construto estratégia neste trabalho é entendido como uma proposição genérica de posicionamento da organização no ambiente competitivo (RUMELT, I979). O construto planejamento estratégico foi operacionalizado pela definição de Mintzberg (I994, p. I2): "procedimento formal para produzir um resultado articulado, na forma de um sistema de decisões integrado". Solicitou-se, primeiramente, aos informantes que descrevessem as atividades do processo de planejamento estratégico da organização. A seguir, pediu-se que detalhassem a seqüência de passos realizada para inserção e aprovação da proposta de projeto associado à decisão estratégica no planejamento. O nível gerencial dos informantes (THOMPSON, I967) foi determinado com base nas descrições de funções de seus cargos (NUTT, I992).

\subsection{ANÁLISE DOS DADOS}

Os casos foram analisados isoladamente e, posteriormente, em conjunto. Os sumários descritivos do processo decisório e do planejamento estratégico e as entrevistas foram estudados utilizando-se a análise de conteúdo categorial. O processo decisório foi descrito utilizando-se o modelo proposto por Mintzberg, Raisinghani e Théorêt (I976) e expandido por Nutt (I992, I993, I998). O planejamento estratégico foi analisado de acordo com as categorias: horizonte e período; atividades e cronograma do ciclo de planejamento; plano operacional e orçamentário; procedimento para implementação de projetos; e relação com o processo decisório estratégico em estudo. A seguir, a tática de construção da explicação foi utilizada na análise cruzada dos casos. Ou seja, induziram-se hipóteses causais, não definitivas, sobre o processo decisório estratégico e sua relação com o planejamento estratégico (YIN, I994; EISENHARDT, I989b). Isso foi feito identificando-se os fatores de similaridade e divergência, por meio das variáveis de interesse, para cada par de organizações estudas (EISENHARDT, I989b). As proposições explicativas foram geradas com base nessas classificações e comparações. Posteriormente, as proposições foram contrapostas a cada um dos casos, para averiguação se os dados confirmavam as relações propostas; em caso afirmativo, permitiam um melhor entendimento da dinâmica existente. As proposições, geradas pelo processo indutivo, foram, então, melhoradas pela literatura disponível. 


\section{AS QUATRO EMPRESAS ESTUDADAS E SEUS PROCESSOS DECISÓRIOS ESTRATÉGICOS}

O Quadro 4 apresenta as quatro empresas componentes da amostra selecionada para estudo. As organizações A, B e D estão entre as maiores empresas do setor de alimentos processados do Estado de São Paulo. A organização C é fornecedora de insumos para a organização B.

\section{QUADRO 4}

EMPRESAS COMPONENTES DA AMOSTRA ESTUDADA

\begin{tabular}{llcc}
\hline EMPRESA & SETOR $^{*}$ & $\begin{array}{c}\text { NÚMERO DE } \\
\text { INFORMANTES }\end{array}$ & $\begin{array}{l}\text { CONTROLE } \\
\text { ACIONÁRIO }\end{array}$ \\
\hline Caso A & $\begin{array}{l}\text { Laticínios. Fabricação de outros produtos } \\
\text { alimentícios. }\end{array}$ & 7 & Estrangeiro \\
\hline Caso B & Produção de sucos de frutas e de legumes. & 3 & Estrangeiro \\
\hline Caso C & $\begin{array}{l}\text { Fabricação de máquinas e equipamentos para } \\
\text { agricultura, avicultura e obtenção de produtos } \\
\text { animais. }\end{array}$ & 4 & Estrangeiro \\
\hline Caso D & $\begin{array}{l}\text { Abate e preparação de produtos de carne e de } \\
\text { pescado. }\end{array}$ & 4 & Brasileiro \\
\hline
\end{tabular}

* Conforme IBGE (2004).

As decisões selecionadas para estudo referem-se à implantação de sistemas. Na organização A trata-se de um sistema tipo CRM; na organização B, um sistema de Gestão da Qualidade; na organização C, um sistema de Serviços de Manutenção; e na organização D, um sistema tipo ERP. Identificaram-se os gerentes mais envolvidos em cada decisão. Dos informantes, I foi gerente da alta administração (gerente geral), II foram gerentes do nível médio, 5 membros do staff (sem autoridade linear), e I gerente do nível operacional. O total de informantes foi de I8 gestores. Embora o espaço impeça a apresentação extensiva dos casos (MCCLINTOCK; BRANNON; MAYNARD-MOODY, I979), se apresentam a seguir, sinteticamente, as quatro organizações estudadas e os sumários descritivos dos processos decisórios validados pelos decisores, elaborados conforme apresentação na Seção 3 sobre a metodologia desta pesquisa. 


\section{ORGANIZAÇÃO A: DEVEMOS CRIAR POLÍTICAS DE RELACIONAMENTO DISTINTAS PARA OS DIVERSOS SEGMENTOS DE MERCADO?}

A organização A é a subsidiária brasileira de um grande conglomerado internacional que atua no setor alimentício. Produz centenas de produtos industrializados no Brasil que comercializa no nível nacional, de forma própria ou via distribuidores.

Em fevereiro de i999, durante uma das reuniões sobre a implementação do projeto automação da força de vendas (aplicação da TI nas atividades do processo de vendas), surgiu a idéia de se segmentarem os clientes com base no relacionamento existente, criando-se políticas de atendimento específicas para cada segmento. Como se tratava de outro projeto (gestão do relacionamento com clientes), as discussões sobre o tema foram postergadas com o objetivo de se envolver a alta administração. Em maio de I999, durante o processo de planejamento estratégico, retomou-se a discussão do projeto, e sua realização foi aprovada e inserida no plano operacional de 2000 . O projeto foi considerado um investimento vinculado à estratégia de diferenciação do produto no canal, via políticas de relacionamento distintas para segmentos-chave do varejo e dos mercados atacadistas. Das seis gerências de segmentos da área de vendas, somente uma aderiu à idéia do novo projeto. As demais juntamente com as filiais regionais se tornaram resistentes em função das mudanças em potencial nas políticas de canal e incentivo. Em julho de I999, o Comitê Diretivo da organização constituiu uma força-tarefa para estudo do tema, composta pela gerência de segmento de vendas favorável ao projeto, pelos Grupos de Usuários das centrais de atendimento aos clientes vinculadas às filiais regionais, que também apoiavam o projeto, e pela área de Tecnologia da Informação (TI). Buscaram-se consultorias que pudessem apoiar o processo decisório, das quais a força-tarefa escolheu uma, por consenso. Em março de 2000 iniciou-se o mapeamento dos processos vinculados à gestão de clientes para a elaboração de uma proposta de integração. A proposta final, detalhando os requisitos funcionais, foi negociada com a força-tarefa. Conflitos entre as áreas usuárias ou impasses gerados na força-tarefa foram resolvidos diretamente pelo executivo principal da organização. A etapa seguinte foi o levantamento pela empresa de consultoria das alternativas de pacotes Customer Relationship Management (CRM), do mercado que atendia aos requisitos funcionais e às restrições da plataforma tecnológica da organização. Surgiram cinco alternativas, que foram avaliadas financeiramente. Uma das propostas foi escolhida pela força-tarefa. Em junho de 2000, um mês antes da data prevista para o início da implementação do projeto no plano operacional, a solução desenvolvida foi 
apresentada formalmente pela força-tarefa ao Comitê Diretivo que autorizou sua realização. Em julho ocorreu a primeira alocação de recurso na implementação da solução, cuja implantação ocorreu seis meses depois.

\subsection{ORGANIZAÇÃO B: PRECISAMOS MELHORAR O SISTEMA DE GESTÃO DA QUALIDADE E SEGURANÇA DO ALIMENTO?}

A organização B é a subsidiária brasileira de um conglomerado internacional que atua na agroindústria. Seu principal produto é o commodity SLCC, isto é, o suco de laranja concentrado e congelado. Noventa e cinco por cento da produção da organização B é exportada para a Ásia e Europa. A gestão da qualidade na organização B é considerada estratégica pelo fato de estar associada à idéia de diferenciação do SLCC no mercado atacadista pela vinculação do lema segurança do alimento à marca via certificação ISO-9000. Em I995, o software para controlar a documentação relacionada à gestão da qualidade passou a apresentar problemas esporádicos e intermitentes. Inúmeras versões corretivas e reuniões com o fabricante foram desenvolvidas, ao longo de três anos. Até que em janeiro de I999, concluiu-se que o software deveria ser substituído em caráter de urgência.

As unidades de negócios da organização-mãe são coordenadas regionalmente por um presidente e um staff, responsáveis pela integração das unidades de cada região e pela gestão das funções-chave. O executivo responsável no staff da América Latina "vendeu" para o presidente regional a necessidade de um Sistema de Software que englobasse toda a gestão da qualidade em cada unidade. Decidiu-se que se faria um piloto na unidade brasileira, constituindo-se uma força-tarefa para estudo do tema e desenvolvimento de soluções. Ela foi formada pelas áreas de operações, qualidade e TI do staff regional, e pelas mesmas áreas da subsidiária brasileira. A força-tarefa estudou a situação existente no Brasil, diagnosticando que as dificuldades se prendiam não só ao software existente, mas também a dificuldades na integração dos processos ligados à gestão da qualidade. Desenvolveu-se uma proposta para melhoria dos processos. Em seguida, contataram-se fabricantes de software, buscando-se alternativas de solução. Identificaram-se, ao todo, nove alternativas, das quais restaram cinco, em função das restrições impostas pela plataforma tecnológica da organização. A escolha do software ocorreu em duas etapas. Na primeira, os cinco fabricantes foram visitados e avaliados pela força-tarefa, que escolheu, por consenso, uma solução. Na segunda fase, reavaliou-se a solução em termos de custo-benefício e riscos. Conflitos ao longo de todo o processo foram resolvidos por negociação entre as áreas. O projeto sobre o sistema de qualidade não foi inserido no processo de planejamento para 2000 em virtude da urgência estabelecida. Após 
análise formal, considerando a estratégia organizacional e a avaliação econômica do projeto, a presidência e controladoria da América Latina remanejaram verbas orçamentárias regionais para a realização do projeto. O projeto foi autorizado pela presidência da unidade brasileira em junho de I999. Ainda em setembro de I999 ocorreu a primeira alocação de recursos para implementação do projeto.

\subsection{ORGANIZAÇÃO C: PRECISAMOS DE UM SISTEMA PARA IDENTIFICAR A FONTE DOS PROBLEMAS QUALITATIVOS NOS PRODUTOS?}

A organização C é uma indústria de transformação que atua no setor de máquinas. Trata-se da unidade de negócios de um conglomerado internacional. A partir de I980 adotou a estratégia de integração para a frente, se reposicionando como uma empresa de serviços, passando a projetar e operar parte do processo produtivo de seus clientes. Os equipamentos continuaram a ser produzidos pela organização, porém, comercializados na forma de arrendamento, como parte do contrato de venda de serviços. A operação técnica dos equipamentos é realizada por equipes técnicas que ficam locadas nas unidades fabris dos clientes, juntamente com estoques de reposição de peças. Em I990, a fábrica, mesmo com turnos extras, não conseguia atender à demanda proveniente do campo por peças de reposição, criando desconfiança interna e dos clientes. Além disso, o ativo peças de reposição atingia taxa de crescimento intolerável. Parecia haver defeitos qualitativos no produto. Porém, não se sabia quais eram as causas: assistência técnica, manufatura, engenharia, módulos mecânicos terceirizados, outros? Criou-se uma força-tarefa para estudar o problema e coordenar o processo de formulação de soluções, composta pelas áreas: engenharia, manufatura, financeira, manutenção e TI. O grupo concluiu pela necessidade de reestruturação dos processos de assistência técnica e implantação de um sistema de informações que permitisse identificar a necessidade de ações corretivas nos processos organizacionais. Destacou-se a importância estratégica desse sistema diante do reposicionamento organizacional. Porém, como a solução consumiria muito tempo, optou-se por desenvolver uma segunda alternativa: identificar e melhorar os componentes cujos problemas causavam maior impacto no custo, via melhorias tanto no nível de produto, como de processo. No final de 1992, quando a situação já estava sob controle, a força-tarefa passou a considerar o desenvolvimento do sistema de informações. Foram, então, contatados os fabricantes de software de manutenção disponíveis no mercado. Como não foram encontrados softwares que atendessem às necessidades funcionais, optou-se pelo desenvolvimento interno. Em I994, houve uma reestruturação na organização: os analistas de sistemas da área de TI foram locados nas áreas usuárias, mantendo uma vinculação funcional com 
a área de TI. O projeto do sistema de informações de manutenção de campo foi alocado na área de finanças, que manteve uma série de conflitos com a área de TI sobre as diretrizes para o desenvolvimento do sistema. Em I995, ocorreu nova reestruturação: o gerente de TI e o gerente financeiro desligaram-se da organização. O gerente de TI não foi substituído. O novo gerente financeiro optou pela contratação de uma empresa de consultoria para assessorar a melhoria dos processos de manutenção e desenvolver o sistema. Em I990 havia se discutido e aprovado, no processo de planejamento, a criação de uma base de informações sobre manutenção de campo que viesse a suportar decisões gerenciais. Embora inserido no plano operacional e orçamentário de i99I e revisado e mantido nos planos de I992 a I995, o projeto do sistema de informações não foi realizado até que se consolidou em I996. Sua implementação foi autorizada pelo gerente geral três meses antes da data alocada no plano operacional de 1996, após reavaliação formal da solução, considerando a estratégia organizacional e avaliação econômica. Em julho de 1996 ocorreu a primeira alocação de capital para implementação do projeto. Sua implantação ocorreu em janeiro de I998.

\subsection{ORGANIZAÇÃO D: O SISTEMA DE INFORMAÇÕES ORGANIZACIONAL SUPORTA A ESTRATÉGIA DE CRESCIMENTO ESTABELECIDA?}

A organização D é uma empresa nacional que atua na agroindústria, no segmento de carnes brancas. No início de I995, durante o processo de planejamento, foi estabelecido como posicionamento estratégico sua inserção no mercado global de carnes. Um dos objetivos estratégicos definidos foi o aumento para o período I995-I998 de 50\% da capacidade produtiva e de 60\% do faturamento. O projeto Gestão Integrada foi um dos recursos estratégicos estabelecidos pelo Comitê Diretivo como um plano de ação para suportar a estratégia de crescimento, tendo como objetivo a melhoria e integração dos processos relacionados às principais funções organizacionais, com base na melhoria dos recursos informacionais. O Comitê Diretivo criou uma força-tarefa para direcionar o desenvolvimento de soluções no processo decisório, constituída pelas áreas de Finanças, Vendas, Operações e Distribuição, Organização de Processos e TI. Em março de 1995 se iniciou o levantamento da situação da organização via reuniões com os usuários. A conclusão do grupo foi que os sistemas existentes não eram adequados para suportar a meta de crescimento proposta. Com base no levantamento realizado, elaborou-se uma proposta de funcionamento integrado dos principais processos organizacionais. Optou-se pela contratação de uma empresa de consultoria de negócios para auxiliar no processo de escolha de um pacote de software Enterprise Resource Planning (ERP), de mercado e, posteriormente, 
realizar sua implantação. Dez pacotes de software ERP foram selecionados. A escolha final deu-se em três etapas. Na primeira, os dez pacotes foram avaliados pela consultoria e pela força-tarefa de acordo com sua funcionalidade e o tempo de implantação. Restaram três alternativas. Na segunda etapa, realizaram-se reuniões de trabalho com as áreas afetadas pela implantação do sistema ERP. A equipe de consultoria visitou cada grupo, expondo as funcionalidades dos módulos correspondentes à área nas três alternativas. Foi escolhida uma alternativa. $\mathrm{O}$ objetivo dessa etapa foi obter o endosso dos formadores de opinião que utilizariam o pacote de software. Conflitos foram resolvidos via negociação e impasses, pelo Comitê Diretivo. Na terceira etapa, aconteceram visitas de avaliação tanto ao fabricante quanto a organizações que já possuíam o pacote de software escolhido, implantado e em funcionamento.

Na organização D, todas as iniciativas aprovadas e inseridas no planejamento que impliquem investimentos importantes são reavaliadas sob o ponto de vista econômico, de acordo com a situação existente, antes de sua implementação. Essa tarefa é formal, ou seja, é documentada explicitamente, e executada por Comitês de Investimento. Existem Comitês de Investimento Regionais, vinculados às filiais, e um Comitê de Investimento Corporativo. Os comitês são compostos por representantes dos principais processos organizacionais tanto no nível regional quanto corporativo. Sua coordenação é da área de Operações. Os comitês têm poder de corte para projetos de qualquer valor e um teto para aprovações. Caso o valor do projeto atinja o teto de aprovação dos comitês regionais, eles podem indicar a aprovação ao Comitê Corporativo. Caso o valor exceda o teto do Comitê Corporativo, ele pode indicar a aprovação ao Comitê Diretivo, ou seja, ao presidente e sua diretoria. Propostas potencialmente estratégicas que não foram consideradas no planejamento do ano fiscal são tratadas como casos excepcionais e também analisadas pelos comitês de investimento. Nesses casos, verbas podem ser remanejadas pelos comitês até o teto de aprovação. Acima desse valor, os projetos considerados importantes são encaminhados para a instância superior com indicação para aprovação.

Embora o projeto de integração dos sistemas de informação tenha tido sua origem no processo de planejamento, em I995, não houve tempo para sua inserção no plano operacional e orçamentário de i996. Após apresentação formal da solução pela força-tarefa, contemplando avaliação estratégica e econômica, o Comitê Diretivo aprovou com o Conselho Administrativo da organização um aporte de capital para realização do projeto. O Comitê Diretivo autorizou a implementação do projeto em março de 1996 . Em abril de 1996 ocorreu o primeiro dispêndio de capital para implementação do projeto, implantado em março de I998. 


\section{A RELAÇÃO ENTRE O PROCESSO DECISÓRIO ESTRATÉGICO E O PLANEJAMENTO ESTRATÉGICO FORMAL}

A seguir são apresentadas as hipóteses explicativas induzidas sobre a questão de pesquisa com base nos resultados encontrados.

\section{A Gênese das Decisões Estratégicas}

Os dados obtidos nesta pesquisa, sintetizados no Quadro 5, mostram que as decisões estratégicas podem se originar dentro ou fora do processo de planejamento estratégico. Nos casos A, B e C, a decisão iniciou fora do planejamento estratégico. No caso D, a decisão iniciou em uma reunião do planejamento estratégico. Em termos formais,

Proposição Pr: As decisões estratégicas não se originam necessariamente no processo de planejamento estratégico.

\section{Planejamento Estratégico e Autorização}

Diversos autores (MINTZBERG; RAISINGHANI; THÉORÊT, I976; MINTZBERG, I994; FREDRICKSON, I984; FREDRICKSON; IAQUINTO, I989) estudaram a fase de autorização do processo de decisão estratégica, concluindo que quando a organização possui planejamento estratégico formal, este se constitui como uma atividade de aprovação. No entanto, os resultados desta pesquisa, apresentados no Quadro 5, indicam que o planejamento não se constitui em uma atividade necessária para implementação de decisões estratégicas. No caso B, o projeto não chegou a ser aprovado no planejamento ou programado no plano orçamentário da organização. A alocação de capital para implementação do projeto ocorreu por meio do remanejamento de verbas orçamentárias. No caso D, o desenvolvimento da solução terminou somente em março de 1996 , o que não permitiu sua programação no planejamento estratégico e plano orçamentário de 1996 (desenvolvido em i995). Como o Comitê Diretivo (presidência e sua diretoria) especificou um prazo de I8 meses para implementação do projeto, foi aprovada uma verba extra-orçamentária para sua realização. A primeira alocação de capital no projeto ocorreu em abril de i996, após sua autorização pelo Comitê Diretivo. 
Outra indicação importante dos dados coletados, conforme o Quadro 5, é que a aprovação de uma decisão estratégica no planejamento e sua programação no plano operacional e orçamentário não são condições suficientes para sua implementação. As decisões são revisadas, imediatamente antes da primeira alocação de capital, em rotina de autorização. Nos casos A e C, as decisões estratégicas foram aprovadas no planejamento estratégico e programadas no plano operacional e orçamentário. No entanto, a autorização final para implementação ocorreu após revisão dos projetos pela alta administração. No caso A, a autorização aconteceu no ano seguinte, um mês antes da data programada no plano operacional para início do projeto. No caso C, a autorização também ocorreu no ano seguinte, três meses antes da data programada no plano operacional. Formalmente,

Proposição P2: A aprovação de uma decisão estratégica no processo de planejamento estratégico e sua programação no plano operacional e orçamentário não são condições necessárias nem suficientes para sua implementação. As decisões são revisadas em rotina de autorização, imediatamente, antes da primeira alocação de capital.

Nos casos A e D, a autorização foi feita pelo Comitê Diretivo, ou seja, o presidente e sua diretoria. No caso C, a autorização foi feita pelo gerente geral. E no caso $\mathrm{B}$, pelo presidente da unidade brasileira e pelo presidente e controladoria da América Latina. Conforme o Quadro 5, os dados indicam que as decisões são autorizadas com base em sua conformidade com as estratégias organizacionais. Em termos formais,

Proposição P3: A autorização de decisões estratégicas ocorre no nível hierárquico da alta administração de acordo com sua conformidade com as estratégias organizacionais.

$O$ resultado geral obtido pode ser sintetizado em um modelo de relacionamento, ainda que introdutório, apresentado na Figura 2, sugerido pelas proposições induzidas dos dados obtidos. 


\section{FIGURA 2}

\section{MODELO DE RELACIONAMENTO ENTRE O PROCESSO DECISÓRIO ESTRATÉGICO E O PLANEJAMENTO ESTRATÉGICO}

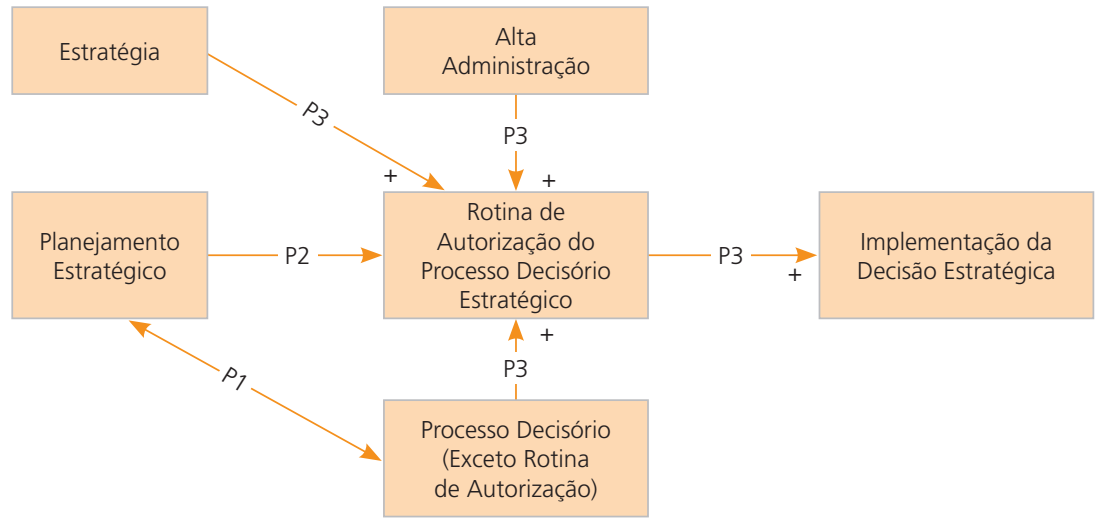

Fonte: Elaborada pelos autores.

As decisões estratégicas de investimento não se originam necessariamente no planejamento estratégico (PI). Sua programação no plano operacional e orçamentário não é condição necessária nem suficiente para sua implementação (P2). Elas são revisadas e autorizadas pela alta administração, antes da primeira alocação de capital, de acordo com sua conformidade com as estratégias organizacionais $\left(\mathrm{P}_{3}\right)$. Este modelo sintetiza as uniformidades observadas nas relações entre as variáveis de interesse (MERTON, I957; WALLACE, I97I).

\section{QUADRO 5}

EVIDÊNCIAS SOBRE A RELAÇÃO ENTRE AS DECISÖES ESTRATÉGICAS E O PLANEIAMENTO ESTRATÉGICO

\begin{tabular}{|c|c|c|c|c|}
\hline CASO & $\begin{array}{l}\text { GÊNESE DAS DECISÕES } \\
\text { ESTRATÉGICAS }\end{array}$ & $\begin{array}{l}\text { PLANEJAMENTO - } \\
\text { CONDIÇÃO NECESSÁRIA }\end{array}$ & $\begin{array}{l}\text { PLANEJAMENTO - } \\
\text { CONDIÇÃO SUFICIENTE }\end{array}$ & $\begin{array}{l}\text { ESTRATÉGIA RELACIONADA } \\
\text { COM A DECISÃO }\end{array}$ \\
\hline $\begin{array}{l}\text { A } \\
\text { Relacio- } \\
\text { namento } \\
\text { com } \\
\text { clientes. }\end{array}$ & $\begin{array}{l}\text { "Discutimos a decisão em } \\
\text { uma reunião do projeto } \\
\text { 'Automação da Força de } \\
\text { Vendas'. Mas, se atacássemos } \\
\text { o problema do CRM, } \\
\text { perderíamos foco. Também } \\
\text { não tínhamos ordem para } \\
\text { tocar." (Gestor de TI) } \\
\text { "No planejamento } \\
\text { [estratégico] o assunto } \\
\text { foi aprovado para o ano } \\
\text { seguinte." (Gestor Financeiro) }\end{array}$ & $\begin{array}{l}\text { "Oportunidades que } \\
\text { não foram planejadas } \\
\text { no orçamento são } \\
\text { avaliadas pela diretoria } \\
\text { e controladoria } \\
\text { corporativa. Eles } \\
\text { podem justificar e pedir } \\
\text { verbas adicionais para } \\
\text { realização." (Gestor } \\
\text { Vendas) }\end{array}$ & $\begin{array}{l}\text { "O projeto já estava no } \\
\text { orçamento e aprovado. } \\
\text { Mas quando chegamos } \\
\text { na solução final, antes } \\
\text { da implementação, a } \\
\text { Diretoria teve que rever } \\
\text { e aprovar o início." } \\
\text { (Gestor Financeiro) } \\
\text { "A controladoria } \\
\text { reavalia os projetos } \\
\text { para garantir que } \\
\text { permanecem OK." } \\
\text { (Gestor Vendas) }\end{array}$ & $\begin{array}{l}\text { "A base da aprovação } \\
\text { foi a estratégia de } \\
\text { diferenciação do } \\
\text { produto no canal, } \\
\text { via políticas de } \\
\text { relacionamento } \\
\text { diferenciadas com } \\
\text { segmentos-chave do } \\
\text { varejo e atacado." } \\
\text { (Gestor Vendas) }\end{array}$ \\
\hline
\end{tabular}




\section{QUADRO 5 (CONTINUAÇ̃̃o)}

\begin{tabular}{|c|c|c|c|c|}
\hline CASO & $\begin{array}{l}\text { GÊNESE DAS DECISÕES } \\
\text { ESTRATÉGICAS }\end{array}$ & $\begin{array}{l}\text { PLANEJAMENTO - } \\
\text { CONDIÇÃO NECESSÁRIA }\end{array}$ & $\begin{array}{l}\text { PLANEJAMENTO - } \\
\text { CONDIÇÃO SUFICIENTE }\end{array}$ & $\begin{array}{l}\text { ESTRATÉGIA RELACIONADA } \\
\text { COM A DECISÃOO }\end{array}$ \\
\hline $\begin{array}{l}\text { B } \\
\text { Quali- } \\
\text { dade e } \\
\text { seguran- } \\
\text { ça do ali- } \\
\text { mento. }\end{array}$ & $\begin{array}{l}\text { "A necessidade de rever } \\
\text { o sistema de qualidade } \\
\text { apareceu em uma reunião } \\
\text { da área de Qualidade. A } \\
\text { coisa estava séria. Havia } \\
\text { muita pressão." (Gestor de } \\
\text { Operações) } \\
\text { "Percebemos que tínhamos } \\
\text { que repensar o sistema de } \\
\text { qualidade em uma reunião } \\
\text { com as áreas." (Gerente } \\
\text { Qualidade América Latina) }\end{array}$ & $\begin{array}{l}\text { "A situação era de } \\
\text { urgência. Não havia } \\
\text { tempo para esperar } \\
\text { o planejamento } \\
\text { [estratégico]. Podíamos } \\
\text { perder acesso a } \\
\text { mercados internacionais. } \\
\text { Remanejamos verbas } \\
\text { regionais." (Presidente } \\
\text { América Latina) } \\
\text { "A verba foi tirada de } \\
\text { outros projetos. Não } \\
\text { dava para esperar." } \\
\text { (Gerente Qualidade } \\
\text { América Latina) }\end{array}$ & $\begin{array}{l}\text { "Todos os projetos do } \\
\text { orçamento expressivos } \\
\text { em recursos só podem } \\
\text { iniciar após aprovação } \\
\text { pelas presidências } \\
\text { da unidade e da } \\
\text { América Latina e da } \\
\text { controladoria regional." } \\
\text { (Gerente Qualidade } \\
\text { América Latina) }\end{array}$ & $\begin{array}{l}\text { "A vinculação da } \\
\text { idéia de segurança do } \\
\text { alimento à marca pela } \\
\text { certificação ISO-9000 } \\
\text { era essencial. Essa } \\
\text { decisão se sustenta } \\
\text { nessa estratégia." } \\
\text { (Gerente Qualidade } \\
\text { América Latina) }\end{array}$ \\
\hline $\begin{array}{l}\text { C } \\
\text { Manu- } \\
\text { tenção } \\
\text { de } \\
\text { campo. }\end{array}$ & $\begin{array}{l}\text { "Percebi que havia um } \\
\text { problema com a conta } \\
\text { [contábil] suprimentos. Estava } \\
\text { muito alta. Comecei a fazer } \\
\text { reuniões para investigar os } \\
\text { processos organizacionais." } \\
\text { (Gerente Geral) } \\
\text { "Descobrimos que não } \\
\text { sabíamos a origem dos } \\
\text { problemas nos produtos. } \\
\text { Começamos a discutir nas } \\
\text { reuniões convocadas pelo } \\
\text { gerente geral." (Gestor de } \\
\text { Vendas) }\end{array}$ & Não há evidências. & $\begin{array}{l}\text { "Como o projeto } \\
\text { estava no orçamento, } \\
\text { esperamos fechar uma } \\
\text { solução para reavaliar e } \\
\text { iniciar." (Gerente Geral) } \\
\text { "Já estava no } \\
\text { orçamento. Foi } \\
\text { re-analisado para } \\
\text { aprovação final." } \\
\text { (Gestor Financeiro) }\end{array}$ & $\begin{array}{l}\text { "Era importante } \\
\text { resolver os problemas } \\
\text { qualitativos no produto } \\
\text { para garantir a } \\
\text { estratégia de integração } \\
\text { para frente. Estávamos } \\
\text { nos reposicionando } \\
\text { como empresa de } \\
\text { serviços." (Gerente } \\
\text { Geral) }\end{array}$ \\
\hline $\begin{array}{l}\text { D } \\
\text { Integra- } \\
\text { ção dos } \\
\text { sistemas } \\
\text { de infor- } \\
\text { mação. }\end{array}$ & $\begin{array}{l}\text { "Na segunda reunião de } \\
\text { planejamento estratégico, } \\
\text { discutimos como viabilizar } \\
\text { a meta de crescimento } \\
\text { estabelecida pelo Conselho. } \\
\text { Aí já discutimos a necessidade } \\
\text { de rever o sistema de } \\
\text { informações." (Gestor TI) } \\
\text { "A discussão começou no } \\
\text { planejamento estratégico." } \\
\text { (Gestor Vendas) }\end{array}$ & $\begin{array}{l}\text { "O projeto foi aprovado } \\
\text { em abril [1996], quando } \\
\text { o plano [orçamentário] } \\
\text { desse ano já estava } \\
\text { concluído. O prazo } \\
\text { para acabar era de } 18 \\
\text { meses. Não dava para } \\
\text { esperar. Foi aprovada } \\
\text { verba extra-orçamento." } \\
\text { (Gestor de TI). } \\
\text { "Foi aprovada verba } \\
\text { extra pelo Conselho } \\
\text { para a realização do } \\
\text { projeto. Não havia } \\
\text { tempo de esperar." } \\
\text { (Gestor Vendas) }\end{array}$ & $\begin{array}{l}\text { "Os projetos do } \\
\text { orçamento passam } \\
\text { pelo comitê de } \\
\text { investimento antes da } \\
\text { implementação. Nesse } \\
\text { caso, pelo valor, o } \\
\text { próprio Comitê Diretor } \\
\text { reavaliou o projeto." } \\
\text { (Gerente Vendas) } \\
\text { "Temos que pensar de } \\
\text { onde sai o dinheiro. } \\
\text { Antes se comprava } \\
\text { jatinho e boa. Hoje há } \\
\text { discussão e tem que } \\
\text { haver consenso. O } \\
\text { processo nos comitês } \\
\text { é documentado." } \\
\text { (Gerente de Operações) }\end{array}$ & $\begin{array}{l}\text { "Garantir a integração } \\
\text { das informações era } \\
\text { necessário para que } \\
\text { pudéssemos crescer } \\
50 \% \text { na capacidade } \\
\text { produtiva, e aumentar } \\
60 \% \text { no faturamento } \\
\text { em } 5 \text { anos. Essa era } \\
\text { a determinação do } \\
\text { Conselho." (Gestor } \\
\text { Vendas) }\end{array}$ \\
\hline
\end{tabular}




\section{CONCLUSÃO}

Esta pesquisa explorou a relação entre o processo decisório estratégico e o planejamento estratégico. Em especial estudaram-se decisões estratégicas vinculadas ao investimento em tecnologia da informação. Como resultado, obteve-se um conjunto de hipóteses causais não definitivas, que estabeleceram um modelo relacionando a implementação das decisões estratégicas, o planejamento estratégico formal, as rotinas do processo decisório estratégico, a alta administração e a estratégia organizacional. Observou-se que para controlar o efeito da dinamicidade das variáveis do ambiente competitivo nas decisões estratégicas as organizações adotam dois procedimentos. O primeiro para decisões inseridas no plano orçamentário e o segundo para oportunidades não contempladas no plano operacional.

No caso de decisões aprovadas no planejamento estratégico e programadas no orçamento, a alta administração posterga a rotina de autorização do processo decisório para imediatamente antes da implementação da decisão. Dessa forma, o processo decisório é estendido além do final do planejamento estratégico, tornando possível a consideração na decisão de eventuais modificações nas variáveis do ambiente competitivo, ocorridas entre a inserção da decisão no plano operacional e o início de sua implementação. Eventualmente, novas avaliações das alternativas de solução podem mostrar que algumas se tornaram inviáveis. Além disso, novas alternativas não disponíveis no período do planejamento estratégico podem ser desenvolvidas. Caso não se chegue a uma solução satisfatória antes da data programada para implementação da decisão, pode ocorrer a extensão da fase de desenvolvimento de soluções; inclusive por um ou mais períodos de planejamento estratégico. Essa situação ocorre quando não existem soluções prontas no ambiente externo da organização e o tempo de adaptação de soluções semiprontas, ou do desenvolvimento de soluções customizadas, é superior ao período de revisão do plano operacional. Nesse caso, do ponto de vista do planejamento estratégico, as decisões são reconsideradas a cada novo ciclo de planejamento.

No caso de uma decisão potencialmente vantajosa que não tenha sido contemplada no planejamento estratégico, a alta administração avalia e autoriza sua implementação em situações de oportunismo estratégico e/ou econômico. Nessas situações, a rotina de autorização inclui a realocação de verbas ou a obtenção de verbas suplementares e o ajuste do plano operacional e orçamentário.

Assim, a aprovação de uma decisão no planejamento estratégico e a programação de sua implementação no plano operacional e orçamentário não constituem condições necessárias nem suficientes para sua implementação.

A rotina de autorização em ambos os casos é formal e baseia-se na conformidade das decisões com a estratégia organizacional e na avaliação econômica 
do projeto. Eventualmente, utiliza-se de comitês de investimento, no nível das unidades de negócio e da matriz, hierarquizados e com responsabilidade limitada pelo valor do capital envolvido nos projetos. Projetos acima de determinados valores são decididos diretamente pelo comitê diretor, composto pelo executivo principal e seus auxiliares diretos.

A aprovação de decisões estratégicas não ocorre no planejamento estratégico, conforme proposto por Mintzberg (I994), mas apenas sua programação no plano operacional e orçamentário, a qual é suscetível de revisão pelas organizações.

Vale destacar as limitações desta pesquisa, as quais estão associadas à metodologia utilizada. Os resultados podem ser considerados válidos para as organizações estudadas. Para outras organizações, os resultados encontrados devem ser encarados como hipóteses não definitivas, a serem confirmadas em pesquisas posteriores.

Para a generalização dos resultados, primeiro seria interessante o desenvolvimento de novas pesquisas qualitativas que pudessem refinar as hipóteses desenvolvidas. São exemplos pesquisas que considerem decisões estratégicas de outra natureza que não o investimento em tecnologia de informação, como decisões sobre novos produtos. Ou pesquisas com empresas vinculadas a outros setores de atividade econômica. Também seria interessante estudar a influência do tipo de comunicação da estratégia e da estrutura organizacional nas rotinas do processo decisório estratégico e na sua relação com o planejamento estratégico. Principalmente, em ambientes dinâmicos e com ruptura tecnológica, como é o caso dos setores de software, telecomunicações e biotecnologia, nos quais a velocidade do processo decisório é crítico para o desempenho. Segundo, seria importante a generalização estatística das hipóteses desenvolvidas com base nessas pesquisas qualitativas. Por fim, caberia a replicação das pesquisas quantitativas.

\section{REFERÊNCIAS}

AL-BAZZAZ, S. J.; GINYER, P. H. How planning works in practice: a survey of 48 UK companies. In: HUSSEY, D. E. (Ed.). The truth about corporate planning. Oxford: Pergamon Press, 1983, p. 2 II-236.

ALLISON, G. T. Essence of decision: explaining the Cuban missile crisis. Boston: Little Brown, I97I.

ALPAR, P.; KIM, M. A Microeconomic approach to the measurement of information technology value. Journal of Management Information Systems, New York, v. 7, n. 3, p. 55-69, I990.

ANDERSON, P. A Decision making by objection and the Cuban Missile Crisis. Administrative Science Quarterly, Ithaca, n. 28, p. 20I-222, I983.

ANSOFF, H. I. Corporate strategy. New York: McGraw-Hill, I965. 
ARENDT, H. On violence. London: Penguin Press, I970.

BAUM, J. R.; WALLY, S. Strategic decision speed and firm performance. Strategic Management Journal, Hoboken, n. 24, p. I.I07-I.I29, 2003.

BIBERMAN, G. Personality and characteristic work attitudes of persons with high, moderate and low political tendencies. Psychological Reports, Missoula, p. I.303-I.310, Oct. I985.

BONOMA, T. V. Case research in marketing: opportunities, problems and a process. Journal of Marketing Research, Chicago, v. 22, p. I99-208, May 1985.

BRYSON, J. M. Strategic planning for public and nonprofit organizations. San Francisco: Jossey-Bass, I988.

BURGELMAN, R. A. A process model of strategic business exit: implications for an evolutionary perspective on strategy. Strategic Management Journal, Hoboken, n. I7, p. I93-2I4, I996.

BUSENITZ, L. W.; BARNEY, J. B. Differences between entrepreneurs and managers in large organizations: biases and heuristics in strategic decision-making. Journal of Business Venturing, Kidlington Oxford, n. I2, p. 9-30, I997.

CARTER, E. E. The behavioral theory of the firm and the top-level corporate decisions. Administrative Science Quarterly, I6, p. 4I3-428, I97I.

CHANDLER, A. D. Strategy and structure: chapters in the history of the industrial enterprise. Cambridge, MA: MIT Press, I962.

CYERT, R. M.; MARCH, J.G. A behavioral theory of the firm. 2nd Ed. Cambridge, MA: Blackwell Publishers, I992.

DEAN JUNIOR, J. W.; SHARFMAN, M. P. The relationship between procedural rationality and political behavior in strategic decision making. Decision Science, Hoboken, Nov/Dec, I993a.

Procedural Rationality in the Strategic Decision Making Process. Journal of Management Studies, Malden, v. 30, n. 4, p. 587-6ro, I993b.

DENNING, B. W. Strategic environmental appraisal. Long Range Planning, London, v. 6, n. I, p. 22-27, Mar. 1973.

EDQUIST, C. The fixed internet and mobile telecommunications sectoral sytem of innovation: equipment production, access provision and content provision. In: MALERBA, F. Sectoral systems of innovation: concepts, issues and analyses of six major sectors in Europe. Cambridge: Cambridge University Press, 2002, p. I55-I92.

EISENHARDT, K. M. Making fast strategic decisions in high-velocity environments. Academy of Management Journal, Briarcliff Manor, v. 32, n. 3, p. 543-576, i989a.

Building theory from case study research. Academy of Management Review, Briarcliff Manor, v. I4, n. 4, p. 532-550, I989b.

EISENHARDT, K. M.; BOURGEOIS, L. J. III. The politics of strategic decision making in top management teams: a study in the microcomputer industry. Academy of Management Journal, Briarcliff Manor, v. 3I, n. 4, p. 737-770, I988.

Charting strategic decisios in the microcomputer industry: profile of an industry star. In: GLINOW, M. V.; MOHRMANN, S. (Eds.). Managing complexity in high technology organizations, systems and people. New York: Oxford University Press, I989, p. 74-89.

EISENHARDT, K. M.; KAHWAJY, J. L.; BOURGEOIS, L. J. III. Conflict and strategic choice: how top management teams disagree. California Management Review, Berkeley, v. 39, n. 2, p. 42-62, winter 1997. 
EISENHARDT, K. M; ZBARACKI, M. Strategic decision making. Strategic Management Journal, Hoboken, n. I3, I992.

ENGEMANN, K. J.; MILLER, H. E. Evaluating information technology investment: a methodology for managing risk. In: MAHMOOD, M. A.; SZEWCZAK, E. J. Measuring information technology investment payoff: contemporary approaches. Hershey: Idea Group Publishing, I999. p. 32I-342. EXAME. As 500 maiores empresas do Brasil. Edição especial. São Paulo, abril 2006.

FREDRICKSON, J. W. The comprehensiveness of strategic decision processes: extension, observations, future directions. Academic of Management Journal, Briarcliff Manor, v. 27, n. 3, p. 445-466, I984.

FREDRICKSON, J. W.; IAQUINTO, A. L. Inertia and creeping rationality in strategic decision processes. Academy of Management Journal, Briarcliff Manor, v. 32, n. 3, p. 516-542, I989.

GLASER, B.; STRAUSS, A. The discovery of grounded theory: strategies for qualitative research. London: Wiedenfeld and Nicholson, I967.

GUP, B. E. Guide to strategic planning. New York: McGraw-Hill, I980.

HANNAN, M. T.; FREEMAN, J. The population ecology of organizations. American Journal of Sociology, Chicago, v. 82, n. 5, p. 929-964, I977.

HAX, A. C.; MAJLUF, N. S. The strategy concept and process: a pragmatic approach. Englewood Cliffs, NJ: Prentice Hall International Editions, I996.

HICKSON, D. J.; BUTLER, R. J.; CRAY, D.; MALLORY, G. R.; WILSON, D. C. Top decisions: strategic decision-making in organizations. San Francisco: Jossey-Bass, I986.

HUBER, G.; POWER, D. J. Retrospective reports of strategic-level managers: guidelines for increasing their accuracy. Strategic Management Journal, Hoboken, n. 6, p. I7I-I80, 1985.

INSTITUTO BRASILEIRO DE GEOGRAFIA E ESTATÍSTICA - IBGE. Classificação nacional de atividades econômicas versão 1.o. 2. ed. Rio de Janeiro: IBGE, 2004.

JUDGE, W. Q.; MILLER A. Antecedents and outcomes of decision speed in different environmental contexts. Academy of Management Journal, Briarcliff Manor, n. 34, p. 449-463, I991.

KHANDWALLA, P. N. The effect of the environment on the organizational structure of firm. I970. Tese (Doutorado)-Pittsburgh: Carnegie-Mellon University, I970.

LANGLEY, A. The roles of formal strategic planning. Long Range Planning, London, 2I:3, p. 40-50, I988.

In search of rationality: the purposes behind the use of formal analysis in organizations. Administrative Science Quarterly, Ithaca, n. 34, p. 598-67I, I989.

MACMILLAN, I. C. Strategy formulation: political concepts. St. Paul: West, I978.

MARCH, J. G.; SIMON, H. A. Organizations. 2nd ed. Cambridge, MA: Blackwell Publishers, I993.

MCCLINTOCK, C. C.; BRANNON, D.; MAYNARD-MOODY, S. Applying the logic of sample sur-

veys to qualitative case studies: the case cluster method, Administrative Science Quarterly, Ithaca,

v. 24 , n. 4, p. 612-629, Dec. I979.

MERTON, R. K. Social theory and social structure. Glencoe: The Free Press, I957.

MILES, R. E.; SNOW, C. C. Organizational strategy, structure, and process. New York: McGraw-Hill, I978.

MILLER, D. Configurations revisited. Strategic Management Journal, Hoboken, v. I7, p. 505-512, I996.

MINTZBERG, H. The strategy concept I: Five Ps for strategy. California Management Review, Berkeley, CA, v. 30, n. I, p. II-24, I987. 
MINTZBERG, H. The rise and fall of strategic planning: reconceiving roles for planning, plans, planners. New York: The Free Press, I994.

MINTZBERG, H.; AHLSTRAND, B.; LAMPEL, J.; Safári de estratégia: um roteiro pela selva do planejamento estratégico. Porto Alegre: Bookman, 2000.

MINTZBERG, H.; RAISINGHANI, D.; THÉORÊT, A. The structure of 'unstructured' decision processes. Administrative Science Quarterly, Ithaca, n. 21, p. 465-499, I976.

NUTT, P. C. Types of organizational decision processes. Administrative Science Quarterly, Ithaca, n. 29, p. 4I4-450, I984.

. Formulation tactics and the success of organizational decision-making. Decision Sciences, Hoboken, n. 23, p. 519-540, 1992.

The identification of solution ideas during organizational decision-making. Management

Science, Hanover, v. 39, n. 9, p. I.07I-I.085, Sept. I993.

How decision makers evaluate alternatives and the influence of complexity. Management

Science, Hanover, v. 44, n. 8, p. I.I48-I.I66, 1998.

PETTIGREW, A. The politics of organizational decision-making. London: Tavistock Publications Limited, I973.

. Longitudinal field research on change: theory and practice. In: NATIONAL SCIENCE FOUNDATION CONFERENCE ON LONGITUDINAL RESEARCH METHODS IN ORGANIZATIONS. I988. Austin, I988.

PFEFFER, J. Managing with power: politics and influence in organizations. Boston: Harvard Business School Press, I992.

PINFIELD, L. T. A field evaluation of perspectives on organizational decison-making. Administrative Science Quarterly, Ithaca, n. 3I, p. 365-388, 1986.

PORTER, M. E. Vantagem competitiva: criando e sustentando um desempenho superior. Rio de Janeiro: Campus, I990.

PRAHALAD, C. K.; BETTIS, R. A. The dominant logic. Strategic Management Journal, Hoboken, n. 7, p. 485-50I, I986.

PRUITT, D. G.; CARNEVALE, P. J. Negotiation in social conflict. Pacific Grove, CA: Brooks/Cole Publishing Cia., I993.

QUINN, J. B. Strategies for Change: logical incrementalism. Homewood, Illinois: Richard D. Irwin, Inc., I980.

RANDOLPH, W. A.; DESS, G. G. The congruence perspective of organizational design. Academy of Management Review, Briarcliff Manor, n. 9, p. II4-I27, I984.

REGER, R. K. et al. Reframing the organization. Academy of Management Review, Briarcliff Manor, n. I9, p. 565-584, I994.

RUBIN, J. K.; PRUITT, D. G.; KIM, S. H. Social conflict: escalation, stalemate and settlement. 2nd. ed. New York: McGraw-Hill Inc., I994.

RUMELT, R. P. Evaluation of strategic: theory and models. In: SCHENDEL, D. E.; HOFER, C. W. (Eds.). Strategic management. Boston: Little Bown, I979, p. I96-212.

SAAP, R.W. Banks look ahead: a survey of banking planning. The Magazine of Bank Administration, Chicago, p. 33-40, July I980.

SEDDON, P. B.; GRAESER, V.; WILLCOCKS, L. P. Measuring organizational IS effectiveness: an overview and update of senior management perspective. Database for Advances in Information System, New York, v. 33, n. 2, p. II-28, Spring 2002. 
SIMON, H. Capacidade de decisão e de liderança. Rio de Janeiro: Fundo de Cultura, I960.

STEINER, G. A. Top mangement planning. New York: Macmillan, I969.

STEINMUELLER, W. E. The European software sectoral system of innovation. In: MALERBA, F. Sectoral systems of innovation: concepts, issues and analyses of six major sectors in Europe. Cambridge: Cambridge University Press, 2002, p. I55-192.

THOMPSON, V. A. Organizations in action. New York: McGraw-Hill, I967.

TUNG, R. L. Dimensions of organizational environments. Academy of Management Journal, Briarcliff Manor, n. 22, p. 672-693, I979.

VON CLAUSEWITZ, C. On war. Princeton: Princeton University Press, I976.

WALLACE, W. L. The logic of science in sociology. Chicago: Aldine-Atherton, I97I.

WEICK, K. E. The social psychology of organizing. Reading, MA: Addison-Wesley, I979.

WITTE, E. Field research on complex decision-making processes: the phase theorem. International Studies of Management and Organization, Armonk, p. I56-182, Summer 1972.

YIN, R. K. Case study research: design and methods. London: Sage, I994.

ZAN, L. What's left for formal planning? Economia Aziendale, Pavia, v. 6, n. 2, p. I87-204, Mar. I987.

\section{TRAMITAÇ ÃO}

Recebido em 05/07/2006

Aprovado em 01/12/2007 